\title{
A GESTÃO DA INFORMAÇÃO NA EDUCAÇÃO A DISTÂNCIA: DESCRIÇÃO DE UMA EXPERIÊNCIA DE ESTÁGIO
}

\author{
Fabio Scorsolini-Comin \\ Felipe José Gameiro \\ Gabriella Peixoto Monarin \\ David Forli Inocente
}

\begin{abstract}
Resumo:
A partir da contextualização da sociedade da informação e dos novos desafios da formação profissional, o objetivo deste trabalho é descrever e discutir uma experiência de estágio profissionalizante na área de Gestão da Informação no contexto da Educação a distância, analisando os seus limites, possibilidades e impactos a partir da apresentação das atividades práticas desenvolvidas pelos estudantes. Participaram do estudo quatro estudantes do curso de Ciência da Informação e da Documentação e Biblioteconomia de uma universidade pública, ao longo de três anos. São descritas as atividades de gerenciamento de informação, desenvolvimento, verificação, controle e manutenção do ambiente virtual, entre outras atividades de suporte na implementação de novos cursos e ferramentas em educação a distância. Com a experiência desses estagiários ao longo do tempo, adquire-se conhecimento e expertise técnicos para a atuação na área de gestão da informação, possibilitando a construção de um agente qualificado para investigar questões como os impactos das novas tecnologias de informação no processo de ensino e aprendizagem. Por fim, esses estudantes adquirem uma visão perspectiva do que se concebe como a gestão da informação em uma empresa da área de educação, passando a refletir a partir de suas experiências, em atenção aos renovados desafios do mercado de trabalho e de uma sociedade em constante transformação, assim como a informação.
\end{abstract}

Palavras-chave:

Ciência da informação; Educação a distância; Formação professional; Estágio

\section{THE INFORMATION MANAGEMENT IN THE DISTANCE EDUCATION: A DESCRIPTION OF A TRAINEE EXPERIENCE}

\begin{abstract}
:
From the context of Information Society and the new challenges of the professional formation, the objective of this work is to describe and discuss a professionalizing traineeship experience in the area of Information Management in the context of the Distance Education, analyzing its limits, possibilities and impacts from the presentation of the practical activities developed by the students. Four students of the Information Science course from a public university had participated in the study throughout three years. The activities of Information Management, development, verification, control and maintenance of the virtual environment are described, among others activities of support in the implementation of new courses and tools in Distance Education. With the experience of these trainees on the three years time, they had acquired knowledge and technical expertise for the performance in the area of Information Management, making possible the construction of a qualified agent to investigate questions as the impacts of the new information technologies in the education process and learning. Finally, these students acquire a perspective vision of what it is Information Management in a company of the education area, starting to reflect from its experiences, in attention to the renewed challenges of the work market and of a society in constant transformation, as well as the information.
\end{abstract}

\section{Keywords:}

Information science; Distance education; Professional formation;. Traineeship 


\section{INTRODUÇÃO}

"Antes mundo era pequeno porque Terra era grande

Hoje mundo é muito grande porque Terra é pequena

Do tamanho da antena parabolicamará

Ê volta do mundo camará, ê mundo dá volta camará (...)”.

(Gilberto Gil, Parabolicamará).

\subsection{As transformações na sociedade da informação}

Este estudo parte de um conjunto de investigações anteriores tanto acerca das transformações da sociedade da informação, com foco na assunção da educação a distância enquanto uma tecnologia aplicada à difusão do conhecimento, quanto de trabalhos acerca da formação de profissionais em um mercado de trabalho em constante mutação, exigindo renovados modos de atuação e de compreensão da realidade profissional (GAMEIRO; SCORSOLINI-COMIN; MATIAS, 2008; GAMEIRO, 2008; SCORSOLINI-COMIN; MATIAS; INOCENTE, 2008; SCORSOLINI-COMIN; INOCENTE; MATIAS, 2007).

As revoluções de natureza tecnológica nunca ocorrem separadas das transformações culturais. Um exemplo disso são os movimentos sociais e culturais das décadas de 60 e 70 que influenciaram decisivamente, embora pudessem ser concebidos independentemente das transformações econômicas e tecnológicas, no modo como se concebem as tecnologias que subsidiaram o atual paradigma informacional (CASTELLS, 2000; BORGES, 2000; BROOK; BOAL, 1995).

O informacionalismo é um paradigma essencialmente tecnológico que não se caracteriza, necessariamente, pelo papel central do conhecimento e da informação na geração de riqueza, poder e significado - o que de certa forma sempre aconteceu em todos intervalos da história humana (CASTELLS, 2003). De acordo com Aguiar (2007), o diferencial desse paradigma tecnológico está ligado às tecnologias de processamento da informação e ao impacto que essas tecnologias induzem na geração e utilização do conhecimento no mundo de hoje.

Neste sentido, Borges (2000) afirma que o conceito de "Sociedade da Informação" nasceu no Japão em princípios da década de 60, quando os especialistas japoneses 
consolidaram uma série de conceitos que adquiriram um novo sentido a partir do grande avanço tecnológico e econômico, bem como das mudanças sociais pós segunda Guerra Mundial. No final dos anos 70, já no contexto europeu, este conceito começa a ser desenvolvido também em consonância com a noção de "Sociedade do Conhecimento". A partir daí, a sociedade da informação enquanto conceito evolui firmemente no discurso ocidental, tornando-se parte essencial das estratégias político-econômicas do atual mundo globalizado.

Segundo Ambrosi, Peugeot e Pimienta (2005), esta expressão reaparece nos anos 90, entre outros, a partir do grande desenvolvimento e aumento da acessibilidade à Internet. É importante destacar que a noção de "sociedade do conhecimento" surge ao final da década de 90 e constitui uma alternativa, segundo alguns pesquisadores, ao uso do termo “sociedade da informação”. A United Nations Educational, Scientific and Cultural Organization (UNESCO) adota a expressão “sociedade do conhecimento”, visando desenvolver uma reflexão em torno de uma concepção mais integral e que esteja desvinculda da vertente econômica (AMBROSI; PEUGEOT; PIMIENTA, 2005). Para os objetivos deste artigo, no entanto, esta distinção não tem papel central. Mais do que isso, é necessário compreender de que modo essas transformações vêm ocorrendo e o modo como elas impactam os modos de produção do conhecimento e, consequentemente, da formação de profissionais que protagonizam tais mudanças.

Em relação a essas transformações, segundo Aguiar (2007), pode-se dizer que junto com o surgimento da atual era da informação, um novo fenômeno surgiu entre as pessoas, empresas e regiões que não têm acesso e participação nas mudanças tecnológicas dessa nova sociedade. Mais especificamente, surgem fenômenos como o da “exclusão digital”, colocando em discussão, também, o potencial transformador dessas tecnologias digitais no seio da sociedade em rede.

Deve-se destacar, neste breve histórico, que ao longo do último quarto do século $\mathrm{XX}$, muito se falou sobre a transição da sociedade industrial para a sociedade da informação. De fato, houve transformações que culminaram em uma atenção especial dada à informação e ao conhecimento, e ao modo como são tratados e valorizados na sociedade. 
De acordo com Werthein (2000), a realidade que os conceitos das ciências sociais procuram expressar refere-se às transformações técnicas, organizacionais e administrativas que têm como “fator-chave” não mais os insumos baratos de energia como na sociedade industrial - mas os insumos baratos de informação propiciados pelos avanços tecnológicos na microeletrônica e telecomunicações. Estas transformações se contextualizam ao cenário de transformações pelo qual o capitalismo atravessa, com ênfase em desenvolvimento de novas tecnologias e na flexibilização das relações entre capital e trabalho.

Este novo panorama possibilita, juntamente, com as variadas alternativas atuais para a comunicação, novos horizontes para o tratamento e disseminação da informação circulante, com um conjunto de públicos-alvo cada vez mais dinâmicos e heterogêneos, ao mesmo tempo em que modifica a abordagem dada ao papel da informação nos mais diferentes segmentos profissionais, sendo estes voltados, cada vez mais, à sociedade da informação.

Dentro deste contexto, em que a informação tem importância fundamental tanto em níveis operacionais como estratégicos, uma empresa não sobrevive sem informação e sem a sua gestão adequada. A gestão pode ser entendida como

[...] um conjunto de processos que englobam atividades de planejamento, organização, direção, distribuição e controle de recursos de qualquer natureza, visando à racionalização e à efetividade de determinado sistema, produto ou serviço. (MANUAL DE GESTÃO DE SERVIÇOS DE INFORMAÇÃO, 1997, apud MARCHIORI, 2002, p.94).

Portanto, ainda segundo este autor,

[...] a Gestão da Informação deve incluir, em dimensões estratégicas e operacionais, os mecanismos de obtenção e utilização de recursos humanos, tecnológicos, financeiros, materiais e físicos para o gerenciamento da própria informação que, a partir disso, deve ser disponibilizada como insumo útil e estratégico para indivíduos grupos e organizações. (PONJUÁN DANTE, 1998, apud MARCHIORI, 2002, p.94).

Pensando nesses desafios atuais e no paradigma da pós-modernidade, na qual a informação ganha um papel de destaque, é importante que se reflita sobre a formação de profissionais capacitados para atuarem dentro das características colocadas pela atual sociedade. 
Nesta discussão sobre os novos modelos da chamada sociedade da informação, Urdaneta (1992) também faz reflexões sobre a sociedade pós-moderna, a que denomina "sociedade inteligente", caracterizando-a como uma sociedade que transforma problemas em soluções, tendo como base o acervo de conhecimento de que já dispõe ou de que possa dispor. Seria uma sociedade que não investiga apenas para conhecer (saber), mas, principalmente, para resolver. Esta sociedade “aprenderia a aprender” atuando.

E esta atuação deve ser pensada, também, a partir da formação profissional.

\subsection{Formação profissional na sociedade da informação}

Neste paradigma da sociedade da informação, cada vez mais há a necessidade de que o mercado de trabalho e, logicamente, o sistema de formação profissional acompanhem as transformações, a fim de que os profissionais não apenas estejam preparados para as novas demandas, mas que possam refletir sobre as mudanças e o impacto das mesmas no sistema de formação e da constituição da própria identidade desses profissionais. Esta ligação entre formação e as mudanças na sociedade já foi discutida por pesquisadores como Ferretti (1997), que enleva a necessidade de rever e dimensionar as relações entre o sistema de formação profissional e o sistema educacional, o que nos remete a compreender de que modo tem-se pensado a formação dos novos profissionais. Esta formação é pensada, na grande maioria, dentro do ensino superior.

Pensando na questão da construção da identidade profissional de uma perspectiva histórico-cultural, ou seja, em contrapartida a uma tendência se conceber a identidade como algo individualizante e descolado da realidade partilhada pelo indivíduo, Bock (1999) destaca que a formação profissional e a cultura na qual estamos imersos favorecem uma concepção de identidade como algo que está em constante construção. Assim, o ser profissional estaria atravessado pelos aspectos culturais e sociais do meio. Se o meio está em constante transformação (advindas, inclusive, da assunção de novas tecnologias), a noção de identidade vai se dar nesse paradigma que não prega a permanência, mas justamente a mudança. Deste modo, Bock (1999) defende que as diferentes profissões devam ser concebidas como em constante transformação, acompanhando as mudanças da realidade social. Ela se refere a esta identidade como movimento, em consonância com teóricos como Paiva (2007), segundo o qual as pessoas

(C) Revista Digital de Biblioteconomia e Ciência da Informação,Campinas, v.7, n. 1, p. 138-162, jul./dez. 2009- ISSN: 1678-765X. 
vão se transformando à medida que interagem com as outras pessoas e outros grupos (SCORSOLINI-COMIN; MATIAS; INOCENTE, 2008).

Assim, deve-se entender que a identidade profissional nunca estará pronta, mas estará sempre acompanhando o movimento da realidade. O desafio de uma profissão, como a de Ciências da Informação e da Documentação, está justamente em identificar-se com as necessidades do mercado de trabalho e acompanhar o movimento destas necessidades, sendo capazes de construir, sempre e permanentemente, respostas técnicas e científicas.

Compreendendo como indissociável a relação entre formação profissional e mercado de trabalho, pode-se apreender as dimensões de educação e trabalho estão cada vez mais ligadas em decorrência do reconhecimento que a educação, ao qualificar os trabalhadores, pode vir a contribuir para o desenvolvimento econômico. Segundo Fogaça (1998), a educação geral e a educação profissional começaram a ser vistas como bastante interrelacionadas, principalmente, pela globalização e pela emergência de um sistema de produção sustentado na automação flexível (SCORSOLINI-COMIN; MATIAS; INOCENTE, 2008).

A partir do trabalho de Gondim (2002), afirma-se que tais mudanças estão levando as organizações formais a se reestruturarem o que, inevitavelmente, repercutem no delineamento de um perfil profissional mais compatível com a nova realidade. O desenvolvimento científico e tecnológico, suporte fundamental da globalização, aumenta a complexidade do mundo e passa a exigir um profissional com competência para lidar com um número expressivo de fatores.

Ainda segundo Gondim (2002), este perfil profissional é baseado em três grandes grupos de habilidades. O primeiro grupo se refere às habilidades cognitivas, comumente obtidas no processo de educação formal (raciocínio lógico e abstrato, resolução de problemas e conhecimento geral). O segundo grupo se refere às técnicas especializadas (informática, língua estrangeira, operação de equipamentos e processos de trabalho) e, por fim, o terceiro grupo contempla as habilidades comportamentais e atitudinais como cooperação, iniciativa, empreendedorismo e ética, por exemplo (SCORSOLINI-COMIN; MATIAS; INOCENTE, 2008).

(c) Revista Digital de Biblioteconomia e Ciência da Informação,Campinas, v.7, n. 1, p. 138-162, jul./dez. 2009- ISSN: 1678-765X. 
Os profissionais dotados dessas capacidades acabam sendo escassos no atual mercado de trabalho, o que suscita, segundo Gondim (2002), a necessidade de se refletir acerca da eficiência no processo de formação e qualificação. A ênfase numa formação generalista e a ampliação das possibilidades de experiência prática durante o curso superior são avaliadas como alternativas para atender a exigência de um perfil multiprofissional e proporcionar a maturidade pessoal e a identidade profissional necessárias para agir em situação de imprevisibilidade, realidade a que estão sujeitas as organizações atuais. Corroborando a reflexão desta autora, questiona-se em que medida este novo paradigma vem sendo incorporado e concretizado na formação universitária. Para Silva e Cunha (2002), a atual sociedade (esses autores utilizam a expressão “sociedade do conhecimento”) traz uma série de transformações significativas ao mundo do trabalho. Cada vez mais, a atividade produtiva depende dos conhecimentos adquiridos e os profissionais devem ser criativos e críticos, estando preparados tanto para agir rapidamente como para se adaptarem no ritmo dessas mudanças.

\subsection{O curso de Ciências da Informação}

Pensando na questão da formação e de que, comumente, os dois primeiros grupos de competências de Gondim (2002) são abordados com maior ênfase, deve-se discutir em que medida pode-se desenvolver também as habilidades propostas no terceiro grupo, em consonância com as demais. Neste sentido, apresenta-se como ponto para reflexão a experiência do estágio profissionalizante em Gestão da Informação na Educação a Distância oferecido pelo Instituto de Ensino e Pesquisa em Administração (INEPAD). Os estagiários desta área são todos estudantes do curso de Bacharelado em Ciências da Informação, da Documentação e Biblioteconomia da Faculdade de Filosofia, Ciências e Letras de Ribeirão Preto - Universidade de São Paulo.

Este curso foi reconhecido em Diário Oficial no ano de 2007, mas é oferecido desde o ano de 2003. Tem duração de 8 semestres, no período noturno, oferecendo 40 vagas anuais, com ingresso pelo vestibular regular da USP. O perfil do curso, segundo informações do site do mesmo (http://www.ffclrp.usp.br), prevê uma sólida formação humanista nas áreas de história e ciências sociais, visando o desenvolvimento de competências para que o profissional da área atue na organização da informação e construção de produtos documentários. O curso visa, ainda, a capacitação para efetuar a 
gestão de unidades de informação, seja no ambiente tradicional, seja no eletrônico, com preparação do futuro profissional para responder a demandas de informação produzidas pelas transformações tecnológicas que caracterizam o mundo contemporâneo (CASTELLS, 2003). O curso oferece suporte para a realização de especializações para o tratamento da informação e da documentação nas áreas de saúde, educação e negócios. Especificamente neste trabalho, abordar-se-á a especialização na área de Educação.

Assim como destacado no delineamento do perfil profissional do cientista da informação, com o advento das "sociedades da informação", as questões informacionais ganharam um novo estatuto e foram colocadas no centro da vida social (AGUIAR, 2007; ARRUDA; MARTELETO; SOUZA, 2000). A informação, uma matéria-prima valiosíssima no mundo atual, é capaz de mobilizar profissionais de diferentes ordens e matizes, imensos investimentos financeiros, tecnologias sofisticadas e variadas, com implicações em leis, políticas e instituições diversificadas. Observa-se uma crescente necessidade de pessoal capacitado para atuação em estruturas, públicas ou privadas, que requerem coleta, armazenamento, organização e apresentação de informações de natureza variada.

O progresso nas diferentes áreas do conhecimento caminha paralelamente ao domínio dos instrumentos de acesso e recuperação da informação e as demandas informacionais dos vários segmentos da sociedade exigem um profissional com formação multi e interdisciplinar (ARRUDA; MARTELETO; SOUZA, 2000).

Ao concluir o curso, o aluno deve estar preparado para atuar em um mercado de trabalho diversificado, influenciado pelas transformações conjunturais e tecnológicas que estão ocorrendo na sociedade. Este profissional deverá enfrentar o desafio de novos ambientes que demandam profissionais com habilidades voltadas principalmente ao acesso à informação.

Ainda de acordo com informações obtidas no regimento do curso, o currículo do mesmo satisfaz os requisitos necessários para a habilitação profissional em Biblioteconomia também, obedecendo às Diretrizes Curriculares para os cursos de Biblioteconomia. Todavia, o curso prepara o aluno para atuar não apenas nos ambientes tradicionais (como bibliotecas públicas, escolares, universitárias, de institutos de pesquisa, empresas e etc.), mas também em ampla variedade de instituições e atividades vinculadas à área de 
informação, como empresas de comunicação e organizações da sociedade civil como sindicatos, movimentos populares, entre outros.

A Especialização em Gestão da Informação e da Documentação na área da Educação oferecido por este curso, especificamente, procura responder à demanda crescente por uma gestão competente de informações e documentos na área, oferecendo elementos consistentes para intervenções no contexto educacional desde os níveis locais até nacionais. Além da contribuição no campo da gestão da informação, da documentação pedagógica, dos acervos bibliográficos, a especialidade em Educação se reveste de particular importância pelo reconhecimento do uso cada vez mais disseminado de novas tecnologias de informação, que se inscreve no rol das questões contemporâneas a serem enfrentadas na formação de professores.

Nesse contexto, um papel importante pode ser destinado à formação de um agente qualificado para investigar questões como os impactos das novas tecnologias de informação no processo de aprendizado. Dessa maneira, mais que oferecer um simples suporte para tomadas de decisões em diferentes níveis, o profissional da especialidade poderá contribuir para o próprio processo de ensino e aprendizagem.

\section{OBJETIVO}

Descrever uma experiência de estágio profissionalizante na área de Gestão da Informação no contexto da Educação a distância. O objetivo do trabalho é justamente apresentar uma iniciativa de estágio, suas características, discutindo seus limites e possibilidades e destacando as implicações do mesmo para a formação de profissionais na área da ciência da informação e suas contribuições para a área da Educação a distância.

\section{MÉTODO}

\subsection{Procedimento}

Far-se-á a descrição e a análise de um estágio profissionalizante na área de Gestão da Informação a partir da apresentação das atividades práticas desenvolvidas pelos 
estudantes que atuam neste segmento em suas rotinas de estágio. Os documentos que subsidiarão esta análise são os planos de estágio extracurricular (convênio empresauniversidade), desenhos de cargo (elaborado pela coordenação da empresa) e avaliações desenvolvidos pelos estudantes participantes (relatórios de estágio) ao longo dos quatro anos (2005-2008) em que este estágio vem sendo oferecido.

\subsection{Local}

Este estágio foi e vem sendo realizado no Instituto de Ensino e Pesquisa em Administração (INEPAD). Este instituto foi criado em 2003 como resultado da parceria de professores de renomadas instituições de ensino que atuaram juntos em diversos programas de formação executiva na modalidade presencial, tais como Universidade de São Paulo (USP), Universidade Estadual de Campinas (UNICAMP), Instituto Tecnológico da Aeronáutica (ITA), Harvard University, Fundação Getúlio Vargas (FGV), Escola Superior de Propaganda e Marketing (ESPM) e Fundação Armando Álvares Penteado (FAAP). É um instituto multidisciplinar com atuação nos segmentos de consultoria, pesquisa e ensino. $\mathrm{Na}$ área de ensino, especificamente, atua no desenvolvimento de cursos de especialização (presenciais e a distância) para diversas áreas do mundo dos negócios, com ênfase em Master of Business Administration (MBAs) executivos in company na modalidade a distância, em parceria com diferentes universidades estaduais e federais do país.

\subsection{Participantes}

Quatro estudantes do curso de Ciência da Informação e da Documentação e Biblioteconomia do Departamento de Física e Matemática da Faculdade de Filosofia, Ciências e Letras de Ribeirão Preto, da Universidade de São Paulo (FFCLRP-USP) que estagiaram e estagiam no INEPAD desde o ano de 2005.

\section{RESULTADOS E DISCUSSÃO}

Neste item, far-se-á a apresentação do estágio, abordando-se as principais características do mesmo, analisando seus aspectos em face da Educação a Distância.

\subsection{Descrição do modelo de educação a distância do estágio}

Este modelo de educação a distância foi inicialmente concebido para a realização de cursos MBA Executivos voltados a funcionários de instituições financeiras, inseridos em 
contexto do oferecimento de programas de capacitação profissional continuada, em nível de pós-graduação lato sensu (Especialização), de forma a promover o desenvolvimento de competências profissionais, capacitando os profissionais dessas instituições no desenvolvimento da carreira e na adequada realização de políticas institucionais.

Este modelo está presentificado em cursos a distância que se valem das seguintes metodologias de entrega de conteúdo: apostilas impressas, videoaulas, Ambiente Virtual de Aprendizagem (AVA) e Encontros Presenciais. A parte mais importante da mediação de aprendizagem se dá por meio do AVA, sistema este controlado totalmente por uma equipe de sistemas da qual fazem parte os estagiários de Gestão da Informação, que são o foco do presente trabalho.

O AVA contém todos os conteúdos programáticos desenvolvidos para as disciplinas e realiza a entrega do Conteúdo Dinâmico, material desenvolvido por técnicos da instituição contratante com o objetivo de aproximar o conteúdo das aulas da realidade efetiva do aluno. O AVA encerra toda a mediação e verificação de aprendizagem, abarcando ferramentas como Chats, Fóruns, Painel de Opiniões, Realização de Avaliações de Reação ao Curso, Realização de Verificações de Aprendizagem e Tarefas diversas. Tais ferramentas, dada a delimitação do presente artigo, não serão aqui abordadas em detalhes, uma vez que o foco é a atuação do estagiário da área de Gestão de Informação, e não as ferramentas por eles desenvolvidas e/ou manipuladas.

O diferencial do Modelo Pedagógico preconizado pelo INEPAD é a operacionalização didática do curso em módulos, disciplinas, temas e aulas. Os módulos são conjuntos de conhecimentos formados por disciplinas. As disciplinas são conjuntos de conhecimentos formados por temas. Cada tema possui três aulas, com a seguinte estrutura: no primeiro dia de aula, há a leitura do texto-base e realização das atividades de Fórum, Chat e Painel de Opiniões, uma ferramenta de interação desenvolvida pelo INEPAD que objetiva realizar a distância o método DELPHI ${ }^{1}$ (o painel possui 3 etapas: na primeira, o aluno emite uma opinião a partir da proposição inicial; na segunda, emite um parecer sobre as opiniões de 5 de seus colegas; na terceira e última, o aluno recebe sua própria opinião avaliada pelos seus colegas. Cabe considerar que a seleção de pareceristas é aleatória e a circularização das opiniões é anônima).

(c) Revista Digital de Biblioteconomia e Ciência da Informação,Campinas, v.7, n. 1, p. 138-162, jul./dez. 2009- ISSN: 1678-765X. 
No segundo dia da aula, o aluno assiste à videoaula e responde à pergunta dissertativa sobre a mesma. Ainda neste dia, o aluno participa da segunda fase do Painel de Opiniões, podendo novamente interagir em ferramentas como Chat e Fórum. No terceiro e último dia, o aluno interage com o Conteúdo Dinâmico, além de realizar a terceira fase do Painel de Opiniões, podendo participar do Chat e do Fórum. O aluno também responde uma Verificação de Aprendizagem a respeito dos conteúdos tratados no tema e faz uma avaliação de reação ao tema.

Tal disposição didática, embora possa parecer contrária a alguns pressupostos da educação a distância, é apontada pelos próprios alunos como um meio de envolvimento e de garantia de cumprimento efetivo das agendas de atividade acadêmica, diminuindo a evasão e organizando a rotina de estudos diários. Assim, destaca-se que tal modelo prima pela regularidade e sistematização, com forte estímulo à construção conjunta do conhecimento, sendo adaptável a diferentes contextos.

\subsection{Arranjos tecnológicos do AVA}

No AVA, organizado e significativamente modificado com base no sistema Moodle ${ }^{2}$, são disponibilizados conteúdos das disciplinas, material das apostilas e conteúdo dinâmico, além de exercícios e provas. O AVA é a sala de aula virtual dos alunos, em que se encontram as diversas funcionalidades para avaliação do curso e interatividade entre os atores envolvidos no processo. O AVA é mantido por múltiplos servidores em rede, como forma de controle. O desenvolvimento da aplicação é baseado no padrão $\mathrm{UML}^{3}$ com

\footnotetext{
${ }^{1}$ Delphi: Método para estruturar um processo de comunicação grupal, de maneira que o processo seja efetivo, permitindo a um grupo de indivíduos como um todo a lidar com um problema complexo (LINSTONE; TUROFF, 1975).

${ }^{2}$ Moodle: Sistema de administração de atividades educacionais destinado à criação de comunidades online, em ambientes virtuais voltados para a aprendizagem colaborativa. Permite, de maneira simplificada, a um estudante ou a um professor integrar-se, estudando ou lecionando, num curso on-line. Nas palavras do criador Martin Dougiamas, baseando-se na pedagogia sócio-construtivista: (...) não só trata a aprendizagem como uma atividade social, mas focaliza a atenção na aprendizagem que acontece enquanto construímos ativamente artefatos (como textos, por exemplo), para que outros os vejam ou utilizem. Disponível em: http://pt.wikipedia.org/wiki/Moodle. Acesso em: 28 jun. 2009.

${ }^{3}$ UML: A Unified Modeling Language (UML) é uma linguagem de modelagem não proprietária de terceira geração. Basicamente, a UML permite que desenvolvedores visualizem os produtos de seu trabalho em diagramas padronizados. Junto com uma notação gráfica, a UML também especifica significados. Disponível em: http://pt.wikipedia.org/wiki/UML. Acesso em: 28 jun. 2009.
} 


\section{ARTIGO}

orientação de objetos. A linguagem de programação utilizada é PHP $^{4}$, largamente aplicada na maioria das plataformas existentes na web. O armazenamento das diversas informações do sistema é feito a partir de um banco de dados MySQL ${ }^{5}$.

Entre os principais arranjos tecnológicos da plataforma, encontram-se os diversos tipos de relatórios de desempenho de alunos e tutores, Chats, Fóruns, Questionários, Frequently Asked Questions (FAQ Geral), Customer Relationship Management (CRM), Pesquisas de Opinião, Fale Com (comunicação entre alunos, monitoria, tutoria e coordenação) e Requerimentos (revisão de nota, afastamentos, reposição de atividades, férias, etc.). Um avanço tecnológico significativo é o Chat de Voz, tecnologia streaming que usa o Windows Media como meio de comunicação.

\subsection{Modelo pedagógico}

O modelo pedagógico do curso parte dos pressupostos da abordagem interacionista de Vygotsky (1984, 1987) e da aprendizagem significativa de Ausubel (1982). A aprendizagem é tratada aqui a partir da Andragogia, considerando a bagagem cultural e social trazida pelos alunos. Na concepção vygotskyana de aprendizagem, deve-se destacar o papel da interação entre os diferentes atores do processo, a fim de que haja a troca entre experiências, saberes e perspectivas. Dentro desta concepção, o presente modelo traz à tona uma ampla possibilidade de interações dentro do ambiente virtual de aprendizagem, com ferramentas que estimulam a comunicação, a troca, os posicionamentos, a reflexão constante. De modo similar, Ausubel (1982) propõe que os conhecimentos prévios dos alunos sejam valorizados para que possa construir estruturas mentais utilizando, como meio, mapas conceituais que permitem (re)descobrir outros conhecimentos, caracterizando, assim, uma aprendizagem prazerosa e eficaz. Ambos pressupostos, portanto, enfatizam a ideia de que o aluno reflete e refrata conceitos que

\footnotetext{
${ }^{4}$ PHP: Termo que significa Hypertext Preprocessor. É uma linguagem de programação de computadores interpretada, livre e muito utilizada para gerar conteúdo dinâmico na internet. Apesar de ser uma linguagem de fácil aprendizagem e de utilização para pequenos scripts dinâmicos simples, o PHP é uma poderosa linguagem orientada a objetos. Disponível em: http://pt.wikipedia.org/wiki/PHP. Acesso em: 28 jun. 2009.

${ }^{5}$ MySQL: O MySQL é um sistema de gerenciamento de banco de dados (SGBD), que utiliza a linguagem SQL (Structured Query Language - Linguagem de Consulta Estruturada) como interface. Disponível em: http://pt.wikipedia.org/wiki/MySQL. Acesso em: 28 jun. 2009.
}

(c) Revista Digital de Biblioteconomia e Ciência da Informação,Campinas, v.7, n. 1, p. 138-162, jul./dez. 2009- ISSN: 1678-765X. 
são por ele vivenciados cotidianamente em suas múltiplas interações com as pessoas, presencialmente ou mediados pelo computador, como é o caso do ensino a distância.

Assim, a partir dessas considerações e amparados pelo pensamento de Knowles (1977), este modelo parte do fato de que os adultos aprendem para solucionar seus problemas, e não por motivos externos, motivo pelo qual desenhou-se um curso voltado para as necessidades educacionais e profissionais dos mesmos, a partir de seus conhecimentos e vivências.

Em termos práticos, o programa se baseia no aprendizado a partir da interação entre diferentes atores, mediada por mídias tecnológicas específicas, como Chats, Fóruns, Painéis de Opiniões e Fale Com, dentro do Ambiente Virtual de Aprendizagem (AVA). Os participantes contam com uma rotina programada de atividades em que se relacionam com seus colegas, tutores e conteúdos, sendo levados a estabelecer teias de conhecimento. Estas teias são estabelecidas por meio de tarefas programadas e sequenciais. Entre os recursos pedagógicos utilizados estão o material didático, a videoaula, a Tutoria, os encontros presenciais e o trabalho de conclusão, todos esses centralizado no AVA.

Os resultados esperados, expressos em termos das habilidades ou competências e declarados nas metas de aprendizagem são analisados a cada disciplina, por meio da metodologia de Kirkpatrick (1976), que avalia subsequentemente as reações, o aprendizado, a mudança de comportamento observável e os resultados do treinamento. As reações são avaliadas semanalmente por meio de diversas verificações de aprendizagem. A mudança de comportamento pode ser medida por meio de avaliações 360 graus junto aos pares dos participantes do modelo (alunos, tutores, monitores, professores, coordenadores). A avaliação de resultado, conforme Hamblin (1978), Abbad e Gama (2001), deve ser feita a partir dos indicadores de desempenho operacional dos participantes.

Tal modelo aqui descrito foi implantado em diversos programas de formação de executivos, com destaque para três programas de MBA in company ofertados a mais de 3.000 alunos em todo o Brasil, a saber: MBA Executivo em Negociação Financeira; MBA Executivo em Operações em Serviços (em parceria com a Universidade de Brasília) e 
MBA Executivo em Negócios do Desenvolvimento Regional Sustentável, em parceria publicada em diário oficial (08/09/2006) com a Universidade de Brasília, Universidade Federal da Bahia, Universidade Federal de Lavras e Universidade Federal do Mato Grosso (quadriênio 2005-2008).

No Ambiente Virtual de Aprendizagem (AVA), em que se dão as interações e os cursos propriamente ditos, o modelo é corporificado na rotina e sequência das atividades e na flexibilização das mesmas, a fim de adequarem-se à demanda do público-alvo. Diversas atividades são desenvolvidas nesta plataforma, dentro de uma sequência de aprendizagem própria do método.

O modelo vem sendo conduzido com resultados expressivos devido a sua contextualização e forte impacto na formação de seus participantes, uma vez que o processo de ensino e aprendizagem, tal como desenvolvido por este modelo em questão, é concebido como sendo uma dimensão da vida do aluno. Deste modo, o aluno não encara o curso como algo externo a ele, mas algo intimamente ligado às suas expectativas e anseios profissionais e pessoais (SCORSOLINI-COMIN; INOCENTE; MATIAS, 2007).

Este modelo está alinhado com as modernas tendências em educação que atestam sobre a necessidade crescente de efetiva comunicação e interação entre os atores do processo de aprendizagem. Partindo da co-construção do conhecimento, tal modelo prima por permitir ao aluno a possibilidade de interagir em diversas ferramentas de modo sistemático, contando com a supervisão de tutores, monitores, professores e coordenadores. A inovação é caracterizada pela possibilidade de dedicação a partir de um sistema controlado de interação que permite a flexibilidade do aluno, colocando-o diante de uma rotina de estudo supervisionada.

\subsection{Descrição e discussão das atividades dos estagiários da área de Gestão da Informação}

De modo simplificado, os estagiários são responsáveis por fazer o gerenciamento de toda a informação disponível no Ambiente Virtual de Aprendizagem (AVA), em cursos que estão em andamento, bem como em novos projetos.

Entre as tarefas específicas desempenhadas pelos estagiários desta área estão:

(c) Revista Digital de Biblioteconomia e Ciência da Informação,Campinas, v.7, n. 1, p. 138-162, jul./dez. 2009- ISSN: 1678-765X. 
a) Gerenciamento de informação:

Neste estágio, o gerenciamento consiste na manutenção, desenvolvimento e manipulação de dados e informações para as diversas finalidades do curso e da plataforma de aprendizagem. Essas informações referem-se tanto a conteúdos educacionais quanto a informações dos bancos de dados que alimentam os sistemas.

Como gerenciador, deve-se destacar que o Gestor de Informação é, na verdade, o mediador da informação, uma vez que ele interliga o usuário da informação (no caso, os alunos) e os elaboradores dos conteúdos (no caso, professores, gestores e supervisores), sendo responsável por maximizar o acesso à informação por parte dos usuários, desenvolvendo estratégias de eficiência e qualidade.

Caracteriza-se, portanto, o papel do Gestor da Informação como agente responsável por desenvolver a Disseminação Seletiva da Informação (DSI), fornecendo aos usuários um produto informacional que atenda a suas expectativas e necessidades. Como exemplo desta fase do trabalho, cabe ilustrar dois itens trabalhados pelos estagiários no processo de melhoria da eficácia da disseminação da informação para os usuários:

1) O Ambiente Virtual de Aprendizagem do MBA Executivo em Negócios do Desenvolvimento Regional Sustentável oferece um espaço (Biblioteca) dedicado à inserção de textos e artigos para oferecimento aos alunos, como suporte para as disciplinas correntes.

Este espaço é baseado na ferramenta do Moodle chamada Glossário, que possui um mecanismo interno de busca e oferece as seguintes categorias para a organização dos arquivos: por ordem alfabética; por categoria (a ser preestabelecida pelo Gestor no momento da criação da ferramenta e, posteriormente, atrelada ao documento adicionado); por data de inserção e por autor. Os documentos são inseridos como um item do Glossário contendo título, resumo e arquivo digital em formato PDF ${ }^{6}$.

\footnotetext{
${ }^{6}$ Portable Document Format (ou PDF) é um formato de arquivo, desenvolvido pela Adobe Systems em 1993, para representar documentos de maneira independente do aplicativo, hardware e sistema operacional usados para criá-los. Um arquivo PDF pode descrever documentos que contenham texto, gráficos e
} 
Embora possua a denominação e o escopo de uma biblioteca, o espaço não correspondia adequadamente no que diz respeito à recuperação da informação, pois, para realizar uma busca eficiente, o usuário deveria conhecer uma ou mais palavras contidas no título ou no resumo do documento, cujo texto poderia não citar necessariamente o assunto ou área de interesse englobada pelo texto integral. Como um paliativo para esta deficiência, concluiu-se fazer um melhor uso da função categoria, acrescentando como tais as disciplinas acompanhadas do respectivo tema (por exemplo: Categoria um: Gestão de Pessoas - Tema 2), uma vez que os documentos disponibilizados são, necessariamente, complementares ao conteúdo das disciplinas. Outra medida tomada foi a inclusão de palavras-chave, que atuam como descritores a serem recuperados no momento da busca, auxiliando a recuperação da informação baseada nos assuntos específicos abordados por cada documento.

1.1) De um modo geral, o AVA se apresenta para o usuário como um ambiente para a realização das atividades regulares dos cursos vigentes. Porém, deve contemplar também todas as funcionalidades necessárias para que o aluno tenha pleno acesso às ferramentas auxiliares no processo de aprendizagem, que vão desde um espaço de descontração com outros alunos até acessos a boletins, requerimentos e ferramentas de comunicação com a coordenação do curso e tutores.

Essa característica tornou necessário o desenvolvimento de um layout que, ao mesmo tempo em que deveria permitir um acesso eficiente às atividades cotidianas do aluno, também deveria contemplar o acesso rápido a outras funções pertinentes aos alunos. Para isto, foram desenvolvidos vários conjuntos de links rápidos, chamados de "box", que ficam situados nas laterais da tela, sendo que o conteúdo principal, ou seja, as aulas, ficam dispostas no centro. Os links que compõem cada box são organizados de acordo com sua finalidade ou característica, de forma a concentrar em um único local diversas opções interconectadas entre si.

Esta medida visa a disponibilização fácil e intuitiva de informações auxiliares que os alunos necessitam com mais frequência, sem, contudo, haver a necessidade de navegação 
por inúmeros links e intrincados sistemas de localização, facilitando a busca pela informação necessária e diminuindo o consumo de tempo neste processo.

b) Desenvolvimento, verificação, controle, e manutenção do ambiente virtual.

Nestas atividades, o estagiário deve desenvolver ferramentas, verificar a adequação e o pleno funcionamento das mesmas, controlando para que cada ferramenta esteja funcionando adequadamente e atendendo aos objetivos propostos. A manutenção do ambiente virtual de aprendizagem (AVA) se refere à constante alimentação e controle das ferramentas e das informações disponíveis neste espaço.

Ao estagiário de Gestão da Informação cabe a tarefa de disponibilizar o conteúdo de uma forma palatável e eficaz, a fim de que o usuário possa acessar a informação sem se deter em detalhes de domínio técnico (uma vez que a maioria dos usuários não possuem um domínio avançado dos recursos do Moodle - os estagiários manipulam este software, a fim de que ele se apresente como AVA, que é um ambiente mais amistoso ao aluno, ou seja, é o "rosto" da plataforma). Esta disponibilização de conteúdos acontece por meio de ferramentas de upload. Todos os conteúdos disponibilizados são de responsabilidade desses estagiários, a partir da indicação e do suporte de áreas anexas à de Gestão da Informação e que possuem o domínio desses conhecimentos de conteúdos do curso.

c) Controle de alunos e tutores:

Os estagiários são responsáveis, ainda, por criar e manter sistemas operacionais de controle de alunos e tutores no AVA, ou seja, controlando seus acessos e envio e participação em atividades previamente definidas no método. Os estagiários possuem o domínio de mecanismos de conferência de participação, cadastro de participantes no AVA e administração técnica dessas informações em bancos de dados.

d) Suporte na implementação de novos cursos e ferramentas:

Como atividade complementar dos estagiários, eles atuam na área de desenvolvimento e implementação de novos cursos e ferramentas técnicas no AVA, a partir de estudos que

(c) Revista Digital de Biblioteconomia e Ciência da Informação,Campinas, v.7, n. 1, p. 138-162, jul./dez. 2009- ISSN: 1678-765X. 
constatam a adequação ou não das ferramentas, bem como a necessidade ou não e alteração nas mesmas.

Com a experiência desses estagiários ao longo do tempo, eles adquirem conhecimento e expertise necessários para a proposição de implementações, uma vez que eles possuem acesso privilegiado aos mecanismos técnicos e experiência no contato com as principais dificuldades relatadas pelos alunos na própria plataforma. Esta é uma área ainda em desenvolvimento pelos profissionais de Gestão da Informação, haja vista que muitos desses conhecimentos são transmitidos por outros profissionais da área de tecnologia e informática e acabam sendo incorporados apenas por eles.

Com este estágio, abre-se a possibilidade de que esses profissionais em formação tenham acesso a esta área em expansão dentro da educação a distância. Infelizmente, pela revisão na literatura realizada neste trabalho, observou-se que há poucos estudos na área de gestão da informação e educação a distância, revelando a premente necessidade de que mais estudos e comunicações sejam elaborados pelos profissionais que atuam no mercado de trabalho (descrição de experiências práticas) e também que produzem o conhecimento acadêmico a respeito, o que vem se mostrando em um movimento muito tímido, apesar da grande relevância do tema.

e) Participação em reuniões de sistemas:

Os estagiários também possuem autonomia para a participação em reuniões de sistemas junto à equipe técnica do curso, com os mantenedores da plataforma e equipe de programadores. Apesar de os estudantes ocuparem posições de estagiários, desempenham também papéis de gestores da área no que se refere à manutenção e ao aprimoramento contínuo do processo de administração das informações na plataforma.

A experiência dos mesmos, em um processo de imersão no sistema e também na área administrativa da empresa os capacita para uma gestão autônoma de seus recursos e da área em si, o que os coloca em uma posição de responsabilidade junto à área, em consonância com os novos desafios do mercado de trabalho e de formação profissional. 
As atividades desempenhadas pelos estagiários, acima elencadas, estão em consonância com as principais premissas da Gestão de Informações, aliadas a uma formação multidisciplinar, com forte tendência para a utilização das tecnologias de informação e comunicação, como preconiza o curso de Ciências da Informação e Documentação.

Entre os principais desafios da área está o efetivo controle do fluxo de informações no AVA, organizando-as e disponibilizando-as de modo prático e didático, mantendo o mesmo nível de detalhamento e acerto em todos os momentos do curso. Isso destaca algumas das limitações do estágio, que é justamente a manutenção do nível de atenção do estagiário no gerenciamento de um grande contingente de informações. Embora haja este grande contingente, tem-se operado com poucos estagiários que atuam nas diversas atividades aqui descritas.

As expectativas referentes à área são justamente a atuação de modo dinâmico e eficaz, a fim de controlar não apenas as informações no AVA, como também promover, implementar e gerenciar novas tecnologias, pensando nas inúmeras possibilidades permitidas pelo sistema.

Esses conhecimentos técnicos devem estar sempre alinhados a uma bagagem de conhecimentos acadêmicos adquiridos na universidade, que justamente colocam a necessidade de interlocução entre os mesmos, promovendo uma formação abrangente e de qualidade, permitindo a assunção de profissionais mais do que consonantes com os desafios do mercado de trabalho, capazes de promover uma reflexão constante acerca da prática profissional e do que representa o papel do Gestor da Informação na sociedade da qual participamos e incorporamos.

\section{CONCLUSÃO}

Deve-se destacar, ao final deste percurso, que a oportunidade de vivência neste estágio tem contribuído positivamente para a formação dos estudantes que dele participam, segundo as avaliações e relatos realizados pelos mesmos durante as supervisões e também nas avaliações do estágio.

(c) Revista Digital de Biblioteconomia e Ciência da Informação,Campinas, v.7, n. 1, p. 138-162, jul./dez. 2009- ISSN: 1678-765X. 
A imersão neste universo de atividades técnicas, com a possibilidade de desenvolvimento de competências gerenciais a partir da autonomia dada ao estagiário, em uma perspectiva diferenciada do que é o processo de trainee (aprendizado em um sentido mais amplo, no qual o estagiário pode se responsabilizar pelo processo de trabalho, assumindo tarefas e a gestão das mesmas, sendo constantemente supervisionado em reuniões de planejamento da área - um processo que, comumente, não é experienciado nas empresas, notadamente em uma área com amplas responsabilidades, notadamente em um curso que se desenvolve no ambiente virtual e tem a plataforma de aprendizagem como principal cenário).

Cada vez mais, observa-se que esses estudantes adquirem uma visão perspectiva do que se concebe como a gestão da informação em uma empresa da área de educação. Deste ponto de vista, ainda, ele passa a refletir sobre a realidade a partir da experiência concreta, de sua imersão, o que se situa dentro da experiência do "ser com”, ou seja, a possibilidade de ser e de criar um ambiente de interação, de troca e de construção de conhecimentos, de ideias e de possibilidades, ou seja, fala-se em co-construção da realidade.

Discute-se, ainda, que o estudante de Ciências da Informação é formado e se forma não apenas com a aquisição de conhecimentos técnicos e específicos de sua área, mas também em outras oportunidades, inserindo-se em projetos na área de educação (educação a distância), por exemplo, permitindo-se não apenas conhecer uma realidade diferente, mas podendo pensar a respeito das inúmeras possibilidades de atuação profissional.

O impacto do estágio, neste sentido, situa o estagiário e futuro cientista da informação como uma pessoa capaz de atuar em diferentes meios e contextos, levando e apreendendo conhecimentos a partir de sua abertura e disponibilidade para o novo, o que deve acontecer constantemente, em consonância com as mudanças na sociedade da informação e também no mercado de trabalho.

Um ponto que deve ser considerado é que a própria profissão do Cientista da Informação ainda é recente. O seu delineamento em termos de perspectivas profissionais ainda se encontra fortemente atrelado a aspectos mais tradicionais, em uma aparente indissociação 
com o curso de Biblioteconomia, por exemplo, como observado no currículo do curso da FFCLRP-USP. Assim, é preciso que o cientista da informação, durante a sua graduação, saiba problematizar a sua formação e construir a sua identidade, identidade esta que passa, necessariamente, por uma transformação em termos de currículo, estrutura, investimento docente e existência de pesquisas voltadas também para essa construção de identidade, como é o caso deste artigo e de outras produções. Essa reflexão deve conduzir esses futuros profissionais a um amadurecimento não apenas da carreira e da sua atuação, mas também do modo como a sociedade encara esses profissionais e como as transformações culturais impactam na reconstrução contínua não apenas da informação, mas dos profissionais ligados a ela.

Como discutido neste relato de experiência, os estágios devem ser concebidos como importantes veículos de formação profissional e de amadurecimento dos graduandos tanto em termos de conhecer o mercado de trabalho, a atuação prática do profissional da informação como também para problematizar a sua intervenção dentro dos limites e das possibilidades oferecidas tanto pelo mercado de trabalho, pela universidade e pelas instituições ofertantes dos estágios.

Destaca-se, neste relato, a escassez de estágios deste tipo, uma vez que essas atividades acima descritas, na maioria das vezes, são desenvolvidas por profissionais contratados, e não por estagiários. A experiência de estágio aqui relatada se situa no sentido de oferecer ao estudante mais do que um treino em técnicas de sistemas de informação no contexto da educação a distância - prima-se, aqui, por permitir ao estagiário o desenvolvimento de competências gerenciais na área da informação e também no desenvolvimento de sistemas, o que situa o estudante dentro de uma nova perspectiva de estágio. Este estágio, deste modo, é uma experiência que atribui ao estudante responsabilidade, autonomia e possibilidade de interlocução com diversos profissionais da área de informação, sistemas e tecnologia (programadores, cientistas da informação e cientistas da computação). A experiência cumpre, assim, o papel de formar profissionais preparados para o mercado e seus desafios, fazendo com que o estágio seja apenas um passo anterior à experiência profissional, e não um passo desconectado de um processo de formação profissional.

Conclui-se que experiências como esta são importantes não apenas para divulgar um mercado de trabalho em ascensão ou uma possibilidade de intervenção, mas justamente 
para possibilitar a reflexão de profissionais da área, docentes, estagiários e estudantes que se apresentam como construtores de um campo em transformação, como a informação, a sociedade, a cultura e o próprio conhecimento.

\section{REFERÊNCIAS}

ABBAD, G.; GAMA, A.L.G. Treinamento: análise do relacionamento da avaliação nos níveis de reação, aprendizagem e impacto no trabalho. Revista de Administração Contemporânea, v.4, n.3, p.25-45, 2001.

AGUIAR, V. M. Os Argonautas da Internet: uma Análise netnográfica sobre a comunidade on-line de software livre do projeto GNOME à luz da teoria da dádiva. 2007. 110 f. Dissertação (Mestrado em Administração) - Escola de Administração da Universidade Federal da Bahia, Salvador, 2007. Disponível_em: $<$ http://www.adm.ufba.br/pub/publicacao/5/MAA/2007/685/DissertacaoGnomeVersaoFi nal.pdf $>$. Acesso em: 30 set. 2007.

AMBROSI, A.; PEUGEOT, V.; PIMIENTA, D. Palabras en juego: Enfoques multiculturales sobre las sociedades de la información. C \& F Éditions, 2005.

ARRUDA, M. C.; MARTELETO R. M; SOUZA D. Educação, trabalho e o delineamento de novos perfis profissionais: o bibliotecário em questão. Ciência da Informação, Brasília, DF, v.29, n.3, p.14-24, set./dez. 2000. Disponível em: <http://www.scielo.br/pdf/ci/v29n3/a02v29n3.pdf> . Acesso em: 27 mar. 2008.

AUSUBEL, D. P. A aprendizagem significativa: a teoria de David Ausubel. São Paulo: Moraes, 1982.

BOCK, A. M. B. A Psicologia a caminho do novo século: identidade profissional e compromisso social. Estudos de Psicologia, v.4, p.315-329, 1999.

BORGES, M. A. A compreensão da sociedade da informação. Ciência da Informação, Brasília, DF, v.29, n.3, p.25-32, 2000. Disponível em: <http://www.ibict.br/cionline/viewarticle.php?id=249>. Acesso em: 28 mar. 2008.

BROOK, J.; BOAL, I. A. Resisting the virtual life: the culture and politics of information. San Francisco: City Lights, 1995.

CASTELLS, M. A Galáxia da Internet: reflexões sobre a Internet, os negócios e a sociedade. Rio de Janeiro: Jorge Zahar Editor, 2003, 243 p.

. A era da informação: economia, sociedade e cultura. In: A sociedade em rede. São Paulo: Paz e Terra, 2000. 
FERRETTI, C. J. Formação profissional e reforma do ensino técnico no Brasil: anos 90. Educação \& Sociedade, v.18, n.59, p.225-269, 1997.

FOGAÇA A. A educação e reestruturação produtiva. In: . (Org.). Políticas de emprego no Brasil. Campinas, SP: Instituto de Economia Unicamp, 1998. p. 30-45.

GAMEIRO, F. J. A avaliação de tecnologias em cursos de especialização na modalidade a distância: reflexões para a prática do profissional da informação. Trabalho de conclusão de curso. Faculdade de Filosofia, Ciências e Letras de Ribeirão Preto, USP, 2008.

GAMEIRO, F. J.; SCORSOLINI-COMIN, F.; MATIAS, A. B. A educação a distância como cenário para a atuação do profissional da informação. Anais do $\mathbf{1 6}^{\circ}$ Simpósio Internacional de Iniciação Científica da Universidade de São Paulo [CD-ROM]. São Paulo, 2008.

GONDIM, S. M. G. Perfil profissional e mercado de trabalho: relação com a formação acadêmica pela perspectiva de estudantes universitários. Estudos de Psicologia, v. 7, p. 299-309, 2002. Disponível em: <http://www.scielo.br/pdf/epsic/v7n2/a11v07n2.pdf>. Acesso em: $27 \quad$ mar. 2008.

HAMBLIN, A.C. Avaliação e controle do treinamento. São Paulo: McGraw-Hill do Brasil, 1978.

KIRKPATRICK, D.L. Evaluation of training. In: CRAIG, R.L. (Org.). Training and Development Handbook. New York: Mc Graw-Hill, 1976. p. 18.1-18.27.

KNOWLES, M. et al. The Adult Learner: the definitive classic in adult education and human resourse development. 5. ed. Texas: Gulf Publishing Company - Houston, 1977.

LINSTONE, H. A.; TUROFF, M. The Delphi method: techniques and applications. Massachusetts: Addison-Wesley, 1975. 640 p.

MANUAL de gestão de serviços de informação. Curitiba: TECPAR/Brasília: IBICT, 1997. 257 p.

MARCHIORI, P. A ciência e a gestão da informação: compatibilidades no espaço profissional. Ciência da Informação, Brasília, DF, v.31, n.2, p.72-79, 2002. Disponível em: < http://www.scielo.br/pdf/ci/v31n2/12910.pdf>. Acesso em: 28 mar. 2008.

PAIVA, G. J. Identidade psicossocial e pessoal como questão contemporânea. Psico, v.38, p.77-84, 2007.

PONJUAN DANTE, G. Gestión de información en las organizaciones: principios, conceptos y aplicaciones. Santiago: CECAPI, 1998. 222 p.

SCORSOLINI-COMIN, F.; INOCENTE, D. F.; MATIAS, A. B. Desenvolvimento regional sustentável e inclusão social: a formação de executivos em programas de MBA 
in company, por meio da educação a distância. Anais do Simpósio Internacional de Ciências Integradas da Universidade de Ribeirão Preto [CD-ROM]. Guarujá, 2007.

SCORSOLINI-COMIN, F.; MATIAS, A. B.; INOCENTE, D. F. A formação profissional de estudantes de Administração: uma experiência de estágio social com jovens abrigados. Revista Brasileira de Orientação Profissional, v.9, n.1, p.103-114, 2008.

SILVA, E.; CUNHA, M. A formação profissional no século XXI: desafios e dilemas. Ciência da Informação, Brasília, DF, v. 31, n. 3, p.77-82, 2002. Disponível em: $<$ http://www.ibict.br/cionline/viewarticle.php?id=185> . Acesso em 27 mar. 2008.

URDANETA, I. P. Gestión de la inteligência: aprendizaje tecnológico y modernización del trabajo informacional. Caracas: Universidad Simon Bolivar, 1992.

VYGOTSKY, L. S. A Formação Social da Mente. São Paulo: Martins Fontes, 1984.132p.

. Pensamento e Linguagem. São Paulo: Martins Fontes, 1987. 157 p.

WERTHEIN, J. A sociedade da informação e seus desafios. Ciências da Informação, v.29, n.2, p.71-77, 2000.

\section{Fabio Scorsolini-Comin}

Psicólogo e Mestre em Psicologia pela Universidade de São Paulo (FFCLRP-USP). Especialista em Gestão da Educação, com ênfase em Administração Escolar. Graduando em Pedagogia pela Universidade de São Paulo (FFCLRP-USP). scorsolini usp@yahoo.com.br

\section{Felipe José Gameiro}

Cientista da Informação pela Universidade de São Paulo (FFCLRP-USP). Gestor da Informação do Instituto de Ensino e Pesquisa em Administração (INEPAD). felipegameiro@gmail.com

\section{Gabriella Peixoto Monarin}

Graduanda em Ciência da Informação, da Documentação e Biblioteconomia pela Universidade de São Paulo (FFCLRP-USP). gaby.usp@hotmail.com

\section{David Forli Inocente}

Mestre em Administração de Organizações pela Universidade de São Paulo (FEARP-USP). Bacharel em Direito pela Universidade de Ribeirão Preto (UNAERP). Gerente de Ensino do Instituto de Ensino e Pesquisa em Administração (INEPAD). forli@inepad.org.br

Recebido em: 09/06/2008

Aceito para publicação em: jan/2009

(c) Revista Digital de Biblioteconomia e Ciência da Informação,Campinas, v.7, n. 1, p. 138-162, jul./dez. 2009- ISSN: 1678-765X. 